\title{
Comparison of secondary equipment redundancy configuration of smart substations in China and overseas
}

\author{
Hao YUAN ${ }^{1, *}$, Min $\mathrm{CHEN}^{2}$, Gang QU ${ }^{3}$,Zhiyuan $\mathrm{GAO}^{1}$ and Yutao Qiu ${ }^{4}$ \\ ${ }^{1}$ China Electric Power Research Institute (Nanjing), Nanjing 210003, China \\ ${ }^{2}$ State Grid Zhejiang Electric Power Research Institute, Hangzhou, Zhejiang 310014 \\ ${ }^{3}$ East China Grid Company Limited, Pudong New District, Shanghai 200120, China \\ ${ }^{4}$ State Grid Zhejiang Electric Power Company Limited, Hangzhou China
}

\begin{abstract}
This paper introduces the overseas smart substation technology scheme, describes the communication network architecture and equipment redundancy configuration in the typical overseas test smart substation scheme, and compares the similarities and differences between China's smart substation redundancy configuration technology and the overseas smart substation configuration technology. The distribution of measurement and control functions of overseas smart substations that are different from China's designs are explained in detail. The different architectures of overseas smart substations and China's smart substations are illustrated. Finally, the suggestions of overseas Smart Substation and China's smart substation are summarized.
\end{abstract}

\section{Introduction}

Because of the rapid improvement of China's substation secondary equipment theoretical research and manufacturing technology level, there are few research contents of substation secondary system overseas introduced. Although the overseas smart secondary equipment technology promotion is relatively slow, there are still some great differences in the design ideas and test methods for the protection, measurement and control function configuration of smart substation compared with those in China [1]. The research on the application of new technologies in overseas substations is usually conservative, and the test scheme is complex, and it can only be allowed to enter the field after sufficient laboratory tests and field trial operation. The whole test process is revised iteratively. The main feature is to select the substation with simple wiring and less impact on the system, make full use of the Bay resources of the substation, and adopt the scheme that can complete the application of various technologies and compare the new and old technologies as far as possible. The technical test process of overseas substation usually needs to go through the process of scheme design, laboratory configuration, closed-loop test, Open-loop test, field test, on-site test run with signal only. Compared with the China's smart substation scheme with various network architecture modes, equipment functions and various integrated layout methods [2-4], the overseas substation technical test process usually takes several years to test the smart secondary equipment by using the expanded secondary bay.
This paper introduces the secondary system scheme of overseas Smart Substation, and provides the redundancy configuration and test method of protection and measurement function for reference.

\section{Overseas test smart substation}

\subsection{Single Line diagram}

The single line diagram of overseas test smart switch station is shown in Figure 1. The connection of substation is relatively simple, which is convenient to expand the test bay of smart secondary system with only minor modification without affecting the normal operation of the original equipment.

\footnotetext{
* Corresponding author:iec60044@163.com
} 


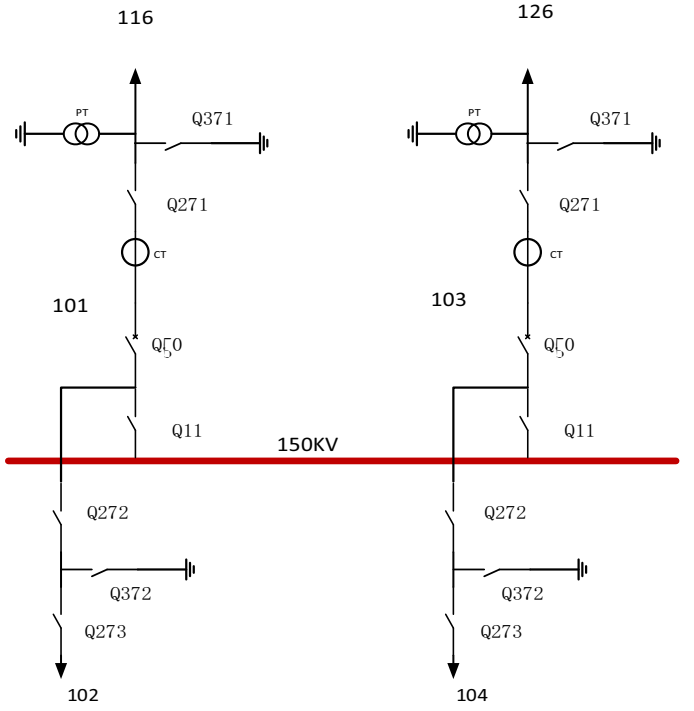

Fig.1 Single line diagram of overseas test substation

The test smart substation is mainly composed of one section of bus, two incoming lines and incoming line switches, and the voltage level is $150 \mathrm{kV}$. The connection of the test substation is simple, the number of bays is small, the voltage level involved is less, and the impact on the system is very small. Compared with the $500 \mathrm{kV}$ Lanxi substation and $220 \mathrm{kV}$ Xijing substation in China, which are 2 early test smart substation in China, the scale and impact are much smaller, but the content of the test is very rich.

\subsection{Secondary system function of overseas test smart substation}

The design of secondary system of overseas test smart substation involves the design of system structure, network architecture, protection, measurement and control function configuration. In order to fully verify the interoperability of secondary equipment, and to investigate the operation status of different manufacturers' equipment integration environment, the equipment from different IED (intelligent electronic device) manufacturers is used. The IED manufacturers within the laboratory test mainly include $\mathrm{Abb}, \mathrm{Ge}$, Effacec (European brand), Siemens, Copadata (monitoring system), Nari (NARI) and switcher manufacturers. The network architecture design adopts the dual design of station control layer and process bus layer. There is a gap compared with China's smart substation network technology application and overseas. [5]

The PACs (protection automation control system) functions involved in the test substation mainly include: line differential main protection and distance backup protection, oscillation locking, fault location, interlocking control, AC voltage and current monitoring, fault waveform recording, breaker failure protection, automatic reclosing, synchronous closing and closing on fault protection (charging protection), time synchronization function, event recording and alarm processing, goose subscription and publishing, SV subscription and publishing, over-current protection, bus protection and phasor measurement, etc. In addition, some manufacturers provide transformer and capacitor protection equipment, with transformer differential protection and backup protection, directional grounding current protection, tap control and over-current load trip. As shown in Table 1, for the function type, the secondary intelligent devices in China's smart substation and overseas are basically the same, the difference is mainly reflected in the function distribution. [6]

Table 1. Main Function Groups

\begin{tabular}{|c|c|c|}
\hline Bay & function & Function description \\
\hline 101 & $\begin{array}{l}\text { local protection and } \\
\text { measurement } \\
\text { control, }\end{array}$ & $\begin{array}{c}\text { line backup protection, voltage, current and } \\
\text { power measurement, reclosing and remote } \\
\text { control }\end{array}$ \\
\hline $\begin{array}{c}101+ \\
116\end{array}$ & $\begin{array}{l}\text { Remote coordination } \\
\text { differential } \\
\text { protection }\end{array}$ & $\begin{array}{l}\text { the main protection of the local side } \\
\text { interacts with the bay } 116 \text { signal of the } \\
\text { opposite side through the IP MPLS channel. }\end{array}$ \\
\hline 101 & metering & Metering MU \\
\hline 103 & $\begin{array}{l}\text { Local protection and } \\
\text { measurement control }\end{array}$ & $\begin{array}{l}\text { in addition to the same function as } 101 \text { Bay, } \\
\text { The traditional protection unit is added in } \\
\text { which the switch signals are from IO and } \\
\text { the analog signals are from PT/CTs. }\end{array}$ \\
\hline $\begin{array}{c}103+ \\
126\end{array}$ & $\begin{array}{l}\text { Remote coordination } \\
\text { differential } \\
\text { protection }\end{array}$ & $\begin{array}{l}\text { main protection local side data is obtained } \\
\text { through Mu unit and goose, and the } \\
\text { opposite side data is also obtained through } \\
\text { Mu unit and goose signal }\end{array}$ \\
\hline 103 & Metering & \\
\hline $\begin{array}{l}150 \mathrm{~K} \\
\text { Vbus }\end{array}$ & Busbar protection & $\begin{array}{c}\text { data of bus protection is from Mu units, and } \\
\text { the digital signals are from CBC and IUD } \\
\text { units }\end{array}$ \\
\hline $\begin{array}{c}\text { statio } \\
\mathrm{n}\end{array}$ & Gateway & $\begin{array}{c}\text { communicates with remote control center } \\
\text { through IEC104 and supports remote access } \\
\text { of IEC } 61850\end{array}$ \\
\hline \multirow[t]{2}{*}{$\begin{array}{c}\text { statio } \\
\mathrm{n}\end{array}$} & $\begin{array}{c}\text { Time } \\
\text { synchronization }\end{array}$ & $\begin{array}{l}\text { the time synchronization system adopts } \\
\text { various schemes to ensure that the time } \\
\text { interval error is less than } 1 \mathrm{~ms}\end{array}$ \\
\hline & Local monitoring & Interlock logic \\
\hline
\end{tabular}

\section{Redundancy architecture of smart substations}

\subsection{Redundancy architecture of overseas smart substation}

The main feature of overseas test smart substation IED configuration is the redundancy configuration of the function system. The diversified IED configuration can be tested under different operating conditions. The redundancy configuration of the test system is not only manifested in the dual configuration of intelligent secondary equipment of different manufacturers and the dual configuration of the network, but also in the redundant parallel application of the traditional equipment and the intelligent equipment.

Figure 2 shows the overall architecture diagram of the overseas test smart substation secondary system. The devices with different colors in the bay 101 in the figure represent different manufacturers. The IEDs including switcheres by different manufacturers are interconnected. During the test in the laboratory, some units were also used for interchange tests. Taking the bay 103 as an example, the network marked in blue is the station control layer communication network, and the network marked in red is the process bus layer communication network with higher reliability with the PRP connection mode. The IEDs are connected to the process bus layer and the station control layer network, and the traditional hard-wired protection equipment is only connected to the 
blue station control layer network. The bay 103 line protective function is designed with dual digital protective relays, and it runs in parallel with the traditional hard-wired protection to complete the comparison of the new and old technology protection functions.

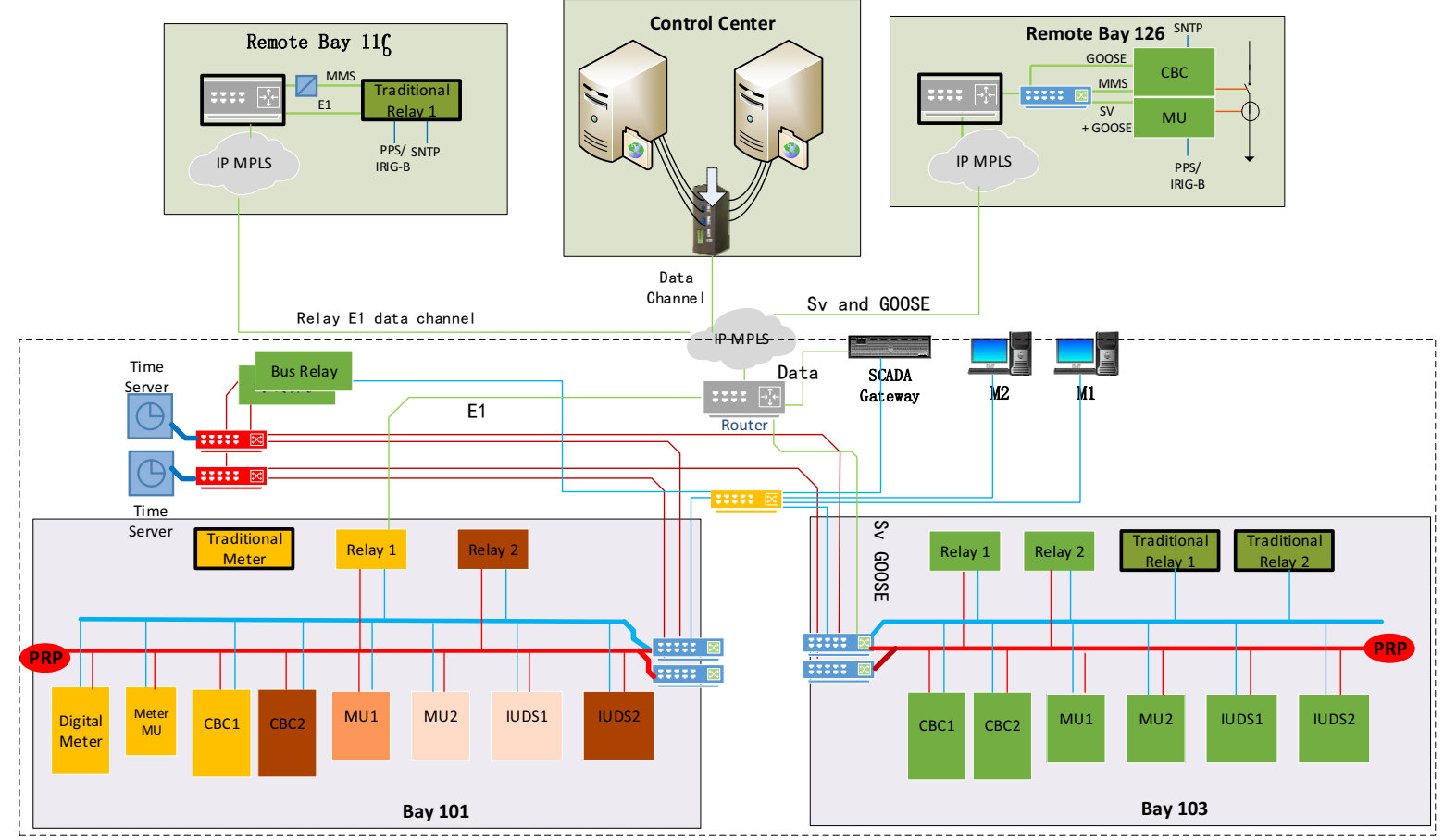

Figure 2. PAC System architecture of overseas test smart substation

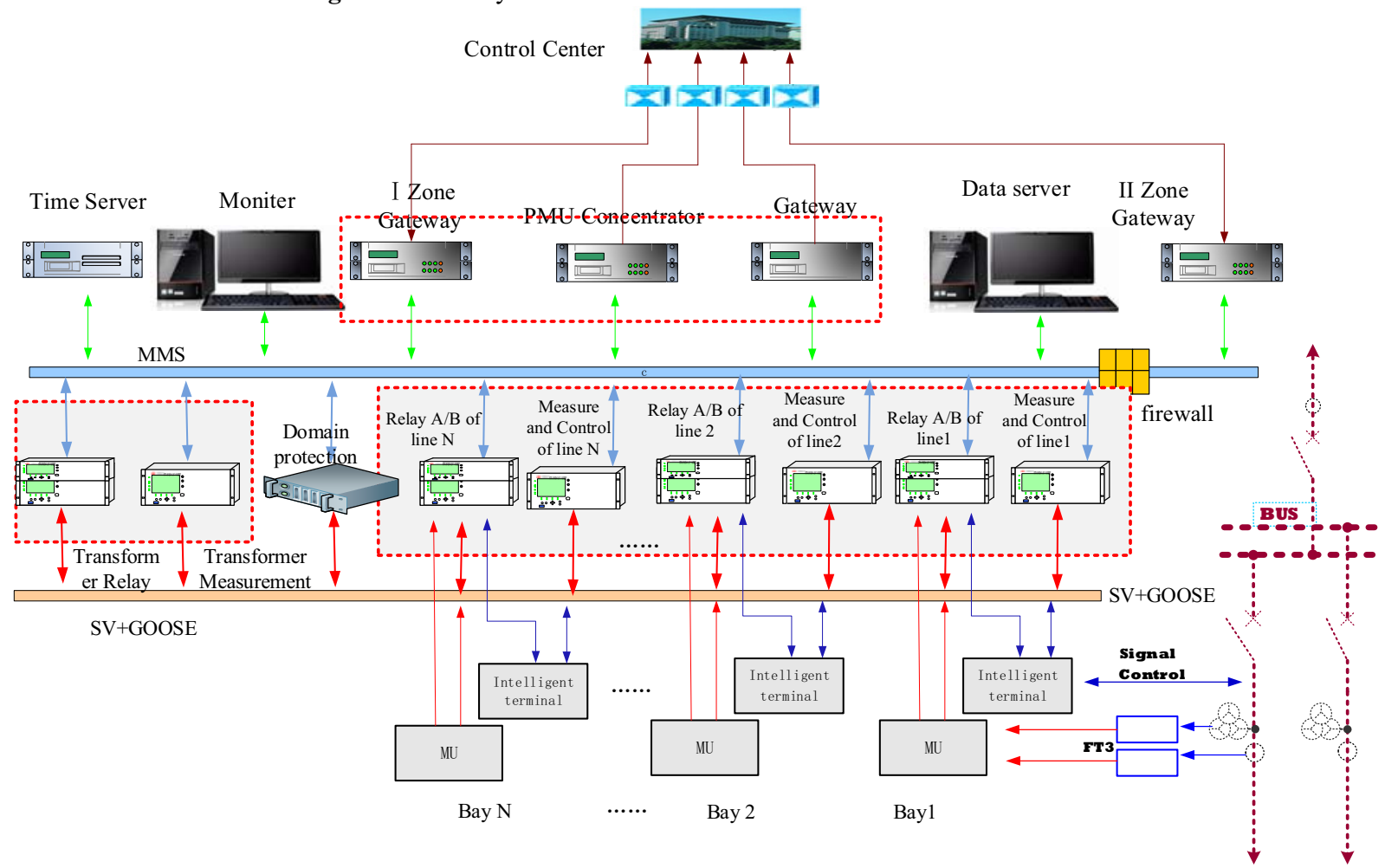

Figure 3. one PAC System architecture of smart substation in China

The redundancy design of the system includes multiple line protection configuration, dual bus protection configuration and corresponding dual process bus layer configuration. It is also reflected in the dual automatic monitoring system configuration and metering equipment configuration. As shown in Figure 2, M1 and M2 are two independent local SCADA monitoring systems. The metering function design, which is quite different from China, adopts a relatively independent metering MU combined with a digital metering device to complete the function. At the same time, a traditional meter is redundantly configured to form a dual metering function. The test smart substation adopted the method of metering MU that satisfies the metering requirements. The metering function operates independently, and solves the controversial issue of metering accuracy when the MU designed for protection, measurement and control is used for the metering function. 


\subsection{Redundancy architecture of smart substation in China}

The protection, measurement and control equipment configured in similar bays of smart substations in China include intelligent terminals, merging units, protection equipment, measurement and control equipment, as shown in Figure 3. In terms of the number of devices, some types of IEDs are with a dual configuration. For example, the actual operation conditions on the site are configurated with dual protective relay scheme. However, the measurement and control unit deployment adopts a single configuration method. A set of measurement and control equipment is connected to a set of MU units and a set of intelligent terminals.[7]

In the overseas design, most of the measurement, control and protection functions are configured in the circuit breaker control unit (CBC), and its position in the substation is similar to that of the intelligent terminal equipment in China's substaition. In addition, IUD equipment (intelligent equipment for disconnector) is designed separately in the overseas test smart substation, which is mainly used to complete the signal acquisition and control for the disconnector. The function of this equipment is usually integrated into the intelligent terminal in China. Compared with the configuration scheme of vertical integration and horizontal integration of secondary equipment, the design of overseas test smart substation is more oriented to the physical primary equipment object. The primary equipment in the bay has corresponding secondary intelligent equipment. Although the number of secondary devices is increased, it is more conducive to the integration of primary and secondary equipment in the future in the long run.

\section{Network architecture}

Overseas smart substation protection, measurement and control equipment usually adopts integrated configuration, and all functions are collectively referred to as PACs. The network architecture of overseas smart substation is relatively simple. The design scheme is that the process bus layer and the station control layer are not physically isolated, the two layers can be interconnected through the switcher. Compared with the design schemes of the early process bus layer network, the local protection network, station control layer and various bay level network, the overseas network scheme is more centralized, more simple, direct and transparent. The network architecture has less divisions of bay, level, function and application. The overseas smart substation also adopts technical means to realize the transmission of different types of data information in the substation, such as goose, $\mathrm{SV}, \mathrm{MMS}, \mathrm{E} 1$ and so on.

At present, the latest smart substation network architectures in China are based on the flow distribution of three networks in one and the two layers of one network technology.

\section{5 conclusion}

Compared with the secondary equipment of traditional PACs, the smart IEDs can better provide relevant functional services to the primary equipment, which is convenient for the fusion design of the primary and secondary equipment in the future. In terms of function redundancy distribution of secondary equipment, the overseas test smart substation has no limitation of separate arrangement of protection and control functions, and the overall implementation efficiency is higher. China needs to break the professional barriers, and more close coordination and cooperation are needed among protection, automation, measurement, communication and other specialties.

\section{ACKNOWLEDGMENT}

Funded by the science \& technology project of State Grid Corporation of China (NO. 5100-201946264A-0-000): Redundancy Strategy and Automatic Testing Technology of Secondary Equipment in Smart Substation"

\section{References}

1. FAN Chen,NI Yimin,SHEN Hong, et al. Comparative Analysis on Development of Smart Substations in China and Europe[J].Automation of Electric Power Systems,2015,39(16):1-7. DOI: 10.7500/AEPS20150303001.

2. WANG Delin,QIU Yutao,LING Guang, et al.Application Scheme and Economical Comparison of Plug \& Play and Outdoor Installation Protection in Substation[J]. Automation of Electric Power Systems,2017,41(16):12-19. DOI: 10.7500/AEPS20170215010.

3. LIU Guowei,LYU Pengfei,WANG Delin, et al.Grounding and Anti-interference Methods of Unprotected Outdoor Installation of Intelligent Electronic Device in Switch Yard[J].Automation of Electric Power Systems,2017,41(16):58-63. DOI: 10.7500/AEPS20170228005.

4. BU Qiangsheng,SONG Shuang,GAO Lei, et al.Development of Assembly Test System for Outdoor Installation Protection Devices[J]. Automation of Electric Power Systems,2018, 42(20):177-183. DOI: 10.7500/AEPS20171115007.

5. ZHENG Yuping,WU Tonghua,DAI Wei, et al. Discussion on Network Architecture of Outdoor Installation Protection System in Substation[J]. Automation of Electric Power Systems,2017,41 (16):20-26. DOI: 10.7500/AEPS20170308001.

6. YUAN Hao,QU Gang,ZHUANG Weijin, et al.Discussion on Condition Monitoring Contents of Secondary Equipment in Power Grid[J]. Automation of Electric Power Systems,2014, 38(12):100-106. DOI: $10.7500 / A E P S 201210277$. 
7. H. YUAN and H. ZHANG, "Design and Deployment of the Redundant Configuration of Substation Automation Measurement and Control Equipment," 2020 Asia Energy and Electrical Engineering Symposium (AEEES), Chengdu, China, 2020, pp. 691-694, doi: 10.1109/ AEEES48850.2020.9121383 